19

\title{
HOW CAN WE IMPROVE TAX INCENTIVES FOR CHARITABLE GIVING? LESSONS FROM FIELD EXPERIMENTS IN FUNDRAISING
}

\author{
Maja Adena
}

\section{Introduction}

When thinking about what tax treatment is optimal for donations, researchers to date have had to rely mostly on cross-sectional or longitudinal data from tax returns in their empirical analysis. Their ability to draw causal conclusions from such data is limited, and they have to rely on relatively strict identification assumptions. Even if the period studied contains tax changes over time, the identification problems will still include the following: all individuals are affected by the tax changes in the same way, different individuals are affected differently, or changes to the tax rate affect both the price of giving and disposable income at the same time. A type of experiment in which a random half of the population would face a different tax rate from the rest of the population in a particular year could provide causal assessment of the policy in question but is rather infeasible.

This is exactly what field experiments with donors to charitable organizations can achieve, even if at a much smaller scale. Recent advances in such experiments can provide us with valuable insights that could also inform the design of the tax code with respect to donations. In this chapter, I connect the literature on the tax treatment of donations with recent field experimental studies in fundraising. Although most of the field experiments I review subsequently are designed with the aim of informing charitable organizations about what works best for their fundraising campaigns ${ }^{1}$ and not with a view to aiding tax authorities, many elements of their designs are similar to the tax code. Such elements include reductions in the price of giving and thresholds for such reduction. The advantage of field experiments is that they allow researchers to arrive at clean causal conclusions without strict identification assumptions that are needed when using naturally occurring data (List, 2008).

Although some of the questions discussed in this chapter have been analyzed in other types of experiments - mostly laboratory but also online and natural experiments - I will not cover these 
(with some exceptions). The reasons for this are as follows: First, covering all the experimental literature would exceed the scope of this chapter. Second, I concentrate on the field experiments because they generally offer a higher external validity than laboratory or online experiments while providing causal inference without relying on potentially restrictive assumptions (in contrast to many natural experiments). There are limitations of relying on field experiments as well. While some might offer innovative designs leading to higher charitable contributions, there might be, of course, other reasons that make the integration of such designs into the tax system not desirable or feasible. And even for uncontroversial and feasible designs, there is no guarantee that they will work when they are integrated into the tax code. The tests in field experiments are usually performed with one organization and one type of potential donor such that the results obtained might differ from general equilibrium results, that is, for all charities and individuals. Still, I believe that reflecting on those studies might be helpful with a view to advancing our thinking about the tax treatment of charitable giving.

I will structure the chapter in the following way. In Section 2, I review studies showing that individuals have a poor idea about their tax-price of giving and that they are inattentive to the tax incentives at the point when they make their donations. In Section 3, I review the literature that studies thresholds for price reduction, including novel approaches based on personalization. In Section 4, I will turn towards the field experiments that compare the effects of price reduction with direct grants to charities. In Section 5, I compare matching with rebate subsidies. In Section 6, I point to the more basic question of whether total donation revenue can be increased or whether taxpayers merely shift donations between recipients and over time as a result of a change in incentives. In the latter case, any change in the tax code with respect to donation treatment would only change the amount of declared donations and not the total amount. Section 7 concludes.

\section{Timing, awareness, and transaction costs}

In several countries, the income tax is designed in such a way that charitable donations reduce taxable income, hence reducing the effective price of giving. The price becomes one minus the marginal tax. This is the case, for example, in the United States and Germany. In practice, this does not necessarily mean that donors have to pay a lower tax on their income at the time when they make the donation but rather that they receive a refund for some part of the donation later. This is the case for many individuals in Germany. The statistical office reports that in 2016, 13.7 million of the approximately 25.5 million individuals subject to income taxation filled in a tax declaration, and of those, 12 million received a refund, ${ }^{2}$ while only 1.5 million had to make a supplementary payment. ${ }^{3}$ The time point at which the individual receives the refund must then necessarily be some time after the donation decision(s). If a person in Germany donates at the beginning of year one, she may not file her tax declaration before the end of February of year three (if she uses a tax advisor or a neighborhood organization that offers tax help). If we assume it takes the tax office another three months to verify the declaration, the difference between the time of donation and a refund might amount to 29 months (and, of course, it might be even longer). Even a person who makes a typical end-of-year donation and timely tax declaration can expect a 5-8-month lag.

Another issue is that taxpayers are unlikely to know their exact marginal tax and thus their individual tax-price for giving until they file their tax declaration and the tax authority approves it. Depending on the complexity of the tax system, this number is difficult to calculate, particularly for donations at the beginning of the tax year, as many income-related factors might 
change (like a pay raise, loss of a job, or changes in family composition). But even for later donations, additional tax-deductible activities might arise or, finally, the tax authority might not recognize some of them. Moreover, donors seldom are reminded of the tax incentives when they make a donation, so they might easily be inattentive or forget about tax benefits. This leads to the following question: To what extent do individuals account for their individual tax-price when making their donations?

Even if a number of empirical studies show that tax incentives are effective in encouraging donations, at least for those with high incomes (see Chapter 12 and references cited therein), it is still unclear what fraction of donations are included in the tax declaration. Clearly, people do not list some donations at all (like money put in a donation box or spare change given to the homeless people), and some individuals might decide ex post on whether to include their donations in the tax declaration. They will not include them if the hassle costs of the deduction (which likely vary over time) are higher than the expected refund value.

To my knowledge, there is only one experimental work devoted to studying those questions in detail. In two large-scale field experiments, Teirlinck (2020) found that donors in Germany are inattentive to tax incentives and hold misperceptions about their individual tax-price. She showed that both making tax incentives salient at the donation stage and providing personalized information increases donations. She also showed that the effect was larger for high-income individuals and that the reason for that was higher hassle costs of tax filing and claiming deductions for low-income individuals. In contrast, in a field experiment in Italy, Casarico and Tonin (2018) documented that mentioning the possibility of a tax deduction in a fundraising campaign reduced donations. This reduction was greatest for small donors, which could relate to transaction/hassle costs as in Teirlinck (2020). The seemingly contradictory results between Teirlinck (2020) and Casarico and Tonin (2018) might arise because of a different content of the information provided (it is much more detailed and personalized in Teirlinck, 2020) or differences between the two countries. This clearly shows that more research on this topic is needed.

\section{Thresholds}

Some tax schemes include minimum thresholds for charitable donations - only donations above the threshold reduce taxable income and thus have lower price. Such thresholds are usually of a fixed value or defined as a percentage of income. Minimum thresholds lead to non-convex budget sets, and such non-convexities have been studied in a number of field experiments. Huck, Rasul, and Shephard (2015) introduced a treatment in which donations above $€ 50$ were matched 1:1 - that is, they had a price of 0.5 - while those below $€ 50$ were not matched and had a price of 1 . They compared this non-convex matching scheme to a linear 1:1 and 1:0.5 matching and other schemes. Using a structural estimation approach, they concluded that if a matching scheme is preferred, then non-convex matching with a lower price for higher gifts outperforms simple linear matching. They also suggested tailoring such matching schemes to the characteristics of potential donors. Such personalization was explored by Adena and Huck (2019a). In a theoretical framework, they showed how personalized thresholds can increase donation values. Such thresholds should be set slightly above the individual's optimal donation in the absence of matching. Of course, in practice, the latter is not observed. The authors proposed to proxy it with past donation values or to estimate it. They tested this idea in a field experiment with past donors and past non-donors. For both groups, they observed a number of individual characteristics. For past donors, they proxied the optimal donation with the past donation and set the threshold for a fixed match amount at different levels relative to this past 
donation. They found that the best results were obtained if the threshold was set at around $60-75 \%$ above the past donation. While such personalization is not feasible and potentially also not desirable for the tax code, they also showed that similar results can be achieved when a fairly small number of individual characteristics are used to set a threshold. They predicted the optimal donation of non-donors by extrapolating from the group of past donors and their individual characteristics. On the basis of this prediction, they set the threshold around the estimated values and obtained similar results to those obtained when the individual past donation was actually known. Again, the most effective threshold was around $75 \%$ above the predicted donation. Stunningly, the amount of information on individuals used for the prediction was fairly limited. How could this idea be applied to the tax treatment of donations? Different thresholds could be implemented depending on, for example, income and the number of children instead of 'one size fits all'. And what if personalized or characteristic-dependent thresholds are not feasible or desirable? Castillo and Petrie (2021) studied an optimal choice of uniform thresholds. In a largescale field experiment and using a structural estimation, they concluded that such thresholds should be set relatively high. While the maximum threshold used in the experiment was $\$ 500$, the estimated optimum threshold should be set at $\$ 2,000$.

As pointed out in Chapter 10, (minimum) thresholds might also impact behavior by imposing a particular norm of giving. Adena and Huck (2019a) discovered that their results from a field experiment with non-personalized thresholds closely followed the patterns from the literature on suggested donation amounts and defaults as reviewed in Adena, Huck, and Rasul (2014). Thresholds and suggestions increase the likelihood that the donation will be the exact or near the suggested value. They lead large donors to reduce their gifts, while small donors increase their donations or abstain (if they see that they are not able to conform to the imposed norm). As a result, the values of donations increase with the level of the threshold, while the probability of donating decreases. The statistical relationship for the total effect is less obvious, but it is likely that the sum of all donations decreases as the threshold value increases. Adena and Huck (2019a) conclude that the latter pattern does not hold if thresholds are properly personalized. The reason is an inverted U-shape relative to the individually optimal donation - the thresholds that are set too low and the thresholds that are set too high are inferior.

\section{The price of giving: matching versus direct grants to charities}

The popular treatment of donations in the tax code results in a deduction that reduces a taxpayer's taxable income and consequently the tax due. This results in a lower price of giving, where the price equals one minus the marginal tax (see Chapter 12 and Chapter 18). On the other hand, charitable organizations often like to attract a major donor before the fundraising campaign and to use this major donor's contribution to leverage subsequent small donations. In many cases, a major donor of this kind commits to matching subsequent donations at a specified match rate (oftentimes 1:1, but sometimes other rates are used) up to a prespecified total amount. There are numerous field (and lab) experiments that study the effects of changes in the price of giving through matching (see Epperson and Reif, 2019, for a thorough review of those studies). In those field experiments, the performance of different matching rates has been tested against a pure control without a major donor or with information about the major donor providing seed money unconditionally.

Two early field experiments tested different matching rates - high matches implying a price of giving of 0.5, 0.33, and 0.25 in Karlan and List (2007) and small matches implying a price of giving of 0.5 and 0.75 in Karlan, List, and Shafir (2011) - against a pure control. While in the first experiment, matching increased the probability of giving and the gift amount relative to 
the pure control, there was no such effect in the second experiment. The authors explain the results as relating to the heterogeneous responses by different types of donors. In both of the field experiments, the changes of the match rate had no effect. The latter result has also been confirmed by Meier (2007), who tested the prices of 0.8 and 0.66 .

In another field experiment with a lead donor control condition, Adena and Huck (2017) showed that matching attracted more donors but that those additional donors predominantly gave small amounts. More importantly, they found substantial crowding out for large donors they reduced their donation amounts when matching was in place. The authors used a lead donor treatment for comparison. They argued that a lead donor treatment should be used because potential donors interpret it as a signal that the charity and its output is of high quality, as they do in the case of matching. In the spirit of Vesterlund (2003), they assumed that the major donor has better information about the quality of the charity and its output and only donates if it is high enough. ${ }^{4}$ Most experiments that rely on pure control for comparisons find that matching performed better, while the studies that used a lead donor treatment for comparisons often found opposite results.

A number of field-experimental studies provide estimates of the price elasticity of giving. However, they use different methods such that the results are not comparable across the studies. Adena, Hakimov, and Huck (2019) calculated the price elasticity for field experiments that used a match rate of 1:1 and a lead donor as a control. Out of five studies, they found the price elasticity to be lower than one in absolute value for three of the experiments (Rondeau and List, 2008; Huck and Rasul, 2011; Gneezy, Keenan and Gneezy, 2014) and higher than one in absolute value for two (Adena and Huck, 2017; Adena, Hakimov, and Huck, 2019). While Huck, Rasul, and Shephard (2015) found that no matching scheme can outperform a lead donor, this conclusion seems to apply only to specific samples, like those made up of rich Western individuals (Adena, Hakimov, and Huck, 2019).

An interesting insight emerged from a field experiment by Meier (2007). He found that matching has a negative long-term effect on donations that can undo the initial positive effect. Donors who were offered matching in year one and did not receive matching in year two reduced their subsequent gifts. The reduction was larger than the initial increase in giving from matching relative to a no-matching control. Meier (2007) argues that matching incentives might crowd out the intrinsic motivation for giving. Other studies, however, did not confirm this negative long-term-effect of matching (Karlan, List, and Shafir, 2011; Kesternich, Löschel, and Römer, 2016).

Another important result is that an announcement of a lead donor always seems to lead to better fundraising results than no such announcement (List and Lucking-Reiley, 2002; Rondeau and List, 2008). This is because (i) the donors are not pure altruists (that is, they do not derive utility solely from all donors' contributions to the public goods) but are (to some extent) warm-glow givers (that is they derive utility from their own donation per se; see Andreoni, 1990). Therefore, there is no crowding out, or it is not complete. (ii) A lead donor provides a signal of quality about the charitable organization and its output, thus leading to higher contributions. A treatment with a lead donor (seed money) resembles direct government grants to nonprofit organizations, and one might be tempted to conclude from the previous line of the field-experimental literature that direct governmental grants should be superior to price reductions. Again, such comparisons are subject to certain limitations, namely that field experiments can only provide partial equilibrium results. Maybe this is why, somewhat in contrast to the experimental literature outlined previously, the empirical literature studying the effects of governmental grants on individual giving has found (incomplete) crowding out (Andreoni and Payne, 2003) rather than crowding in. 
Finally, in order to reduce crowding out, Adena and Huck (2017) proposed an innovative design in which the matching amount is not going to the same project but to another, ideally complementary, one. What kind of similar design is plausible for the tax code? One option is for the tax subsidy to benefit other social projects directly instead of being paid back to the donors.

\section{Matching versus rebates}

Matching is sometimes offered by a major donor who matches gifts to a charity directly or by employers who encourage payroll giving. In contrast, the preferential treatment of donations in the U.S. and German tax code takes the form of a rebate. In the UK tax system, both subsidy types exist in parallel - donations of UK taxpayers are matched at a rate of $25 \%$ up to the tax due amount, and eventually the rebate subsidy applies. Matching and rebates are both mathematically equivalent, and both reduce the price of giving. But they differ in the implementation - that is, in the timing and which actions are required by the donor for the subsidy to apply. While matching usually happens instantaneously and the donor usually does not need to take any action, the rebates are paid out much later and require the donor to claim donations in their tax declaration. Do those two instruments have the same effect on donors?

Throughout the experimental literature, rebates consistently perform worse than matching. This was shown, among others, by Eckel and Grossman (2003, 2006, 2008, 2017) both in the laboratory and field experiments. The inferiority of rebates was even higher in field experiments, where the rebate takes more time to materialize (Eckel and Grossman, 2008). See Vesterlund (2016) for a thorough review of the experimental literature on this topic and Chapter 20, of this Handbook for a laboratory study. ${ }^{5}$ This raises a question: Why are rebates inferior to matches?

In order to understand the reasons behind the differences in the effectiveness of matches and rebates, Eckel and Grossman (2017) introduced a small twist into the design of their field experiment: The donors had to tick a box if they wanted the subsidy - matching or rebate - to materialize. Only $56 \%$ of donors ticked the box, and donors in the match treatments were twice as likely to do so. The authors suggested different explanations for the observed responses: they pointed to a lack of awareness of the incentives, an unwillingness to accept a subsidy, misperceptions, or a reluctance to deal with the additional costs of cashing in a rebate check. Those reasons may potentially lead to differences between the responsiveness to match versus rebate incentives. The researchers found a much lower price elasticity in the case of rebates - they were less than one in absolute value, while price elasticities in the matching treatments were estimated to be above one in absolute terms. However, when they only accounted for the donors who accepted the subsidy, the price elasticity estimates were very similar and very high. Ottoni-Wilhelm and Hungerman (2021) offer a different explanation for the non-equivalence between the match-price elasticity and the rebate-price elasticity. According to their theoretical model, the donor cares about the impact of the amount received by the charity (which includes the matched amount in the case of matching) and gets warm-glow utility from their own gift. While the rebate affects the opportunity cost of both the impact and warm glow, the match reduces the cost of impact but does not alter the cost of one's out-of-pocket donation.

All together, the experimental results suggest that encouraging charitable giving in the tax code through deductions might be inferior to other simple alternatives. A potentially better solution would be instead to allow donors to communicate their tax number together with a donation and for the charities to cash in the match. If there is a reason to prefer rebates in the tax code, Thaler und Sunstein $(2008$, p. 230) propose the following simplification: an introduction of a charity debit card which would be only used for donation payments. Each donor would 
receive a summary at the end of the year which they could simply add to their tax declaration. This would reduce the additional transaction costs, which might explain the differences in the performance between rebates and matches. Richard Thaler ${ }^{6}$ has made a further proposal regarding the simplification of how donations are treated in the tax code. Instead of differential incentives for those with high versus low incomes (see Chapter 10 for a discussion), he proposes a fixed subvention of $15 \%$ for each and every donation, including those made by individuals who do not pay any taxes.

\section{Is the total donation pie constant?}

The effect of incentives for charitable giving in the tax code depends crucially on whether the donation pie is constant. Even if a change in tax incentives leads to a change in the volume of claimed donations, it is possible that it merely leads to a shift between the claimed and unclaimed donations, eligible and ineligible beneficiaries, or over time. Truly increasing total donations would require reducing spending on other goods (assuming a constant budget), ideally on those which are not desirable from the society's point of view (Heger and Cornish, 2021; Schmitz, 2021). This leads to another important question that has become topical but is difficult to answer. Is the total donation pie constant, or can it be made bigger?

Field experiments that observe giving to only one charity in the short term do not allow us to answer this question. What happens to giving to other charities if one charity increases its fundraising activities or offers additional incentives for giving? In a field experiment with blood donations, Lacetera, Macis, and Slonim (2012) found that individuals went to blood drives that offered incentives like a t-shirt or lottery ticket and avoided those without incentives while keeping their total blood donation volume constant. Adena and Hager (2020) conducted a field experiment with fundraising activities for one organization in a random half of the zip codes in Germany. They also analyzed zip code-level data for a large fraction of donations to other organizations. They found a significant crowding out of donations to other organizations of a similar type, which points to crowding out and a limited scope to expand the donation pie. ${ }^{7}$

Another take on the total giving question is offered by studies that look at giving over time. Adena and Huck (2019b) studied whether inducing a donor to give more today leads them to reduce their giving later on. Initially, they documented that individuals who were informed about a future fundraising campaign reduced their giving in the first year as if they were planning their long-term giving. However, individuals in the second year gave similar amounts to their first-year amounts. ${ }^{8}$ This means that, ultimately, they did not optimize over time. Similarly, Shang and Croson (2009) found that new donors who learned about a high donation that was given by a previous donor gave more, and they did so again a year later without receiving such information. This means that increasing giving today leads to more giving tomorrow and contradicts the fixed-budget hypothesis. In comparison, the findings from the empirical literature on tax-price incentives suggest that taxpayers do account for future and past changes in their individual tax-price to some extent (see again Chapter 12).

All together, the experimental results presented previously are inconclusive ${ }^{9}$ and suggest that more research is needed.

\section{Conclusions}

Researchers have long called for tax reform with respect to the treatment of donations (Saez, 2004). The results from the field experiments presented previously call into question several design elements of the tax treatment of donations: the complexity and timing, the price 
reduction for giving through deductions, and the somewhat random setting of thresholds for deduction. Still, the previously reviewed studies cannot provide the ultimate answer for how to optimally incentivize giving through taxes, as they are not designed to do so. While there are a number of existing field experiments with taxpayers meant to enhance tax compliance (Iyer et al., 2010; Gangl et al., 2014; Dwenger et al., 2016; Bott et al., 2019), to my knowledge, no one has conducted a real-world field experiment that varies the tax incentives for giving. ${ }^{10}$ There may be scope for this, and for this reason, more research of this type is needed.

\section{Notes}

1 Another reason is to understand better the motivation of donors, though laboratory experiments are sometimes a better option to that end.

2 There are, of course, other reasons than charitable giving that might lead to a refund.

3 https://www.destatis.de/DE/Themen/Staat/Steuern/Lohnsteuer-Einkommensteuer/im-fokus-steuererklaerung.html (accessed on 19.01.2021).

4 See also Adena et al. (2017) for quality certification.

5 There are two studies with different designs that achieve equivalence of rebate and matches. The first is in the context of unit donations (Diederich et al., 2020), and the second relies on framing contributions in terms of charity receipts and not refunds (Davis, 2006).

6 18.12.2017, Richard R. Thaler, "It's Time to Rethink the Charity Deduction" https://nyti. $\mathrm{ms} / 2 \mathrm{pmvncz}$ (viewed on 20.10.2017).

7 In contrast, in the small world of a laboratory experiment, Schmitz (2021) found that matching incentives shifted donations towards charities that offer price reductions but that the overall donations remained constant. In an experiment with survey participants, an extra budget for charitable giving provided by the researchers, and two charities, Gallier et al. (2019) found that matching raised overall donations.

8 Such positive path dependence has been also found in an online experiment by Heger and Slonim (2020).

9 See also Gee and Meer (2020) for a more detailed review of further literature on this topic.

10 There are experiments outside the lab that try to mimic the real tax context, for example, (Becchetti, Pelligra, and Reggiani 2017).

\section{References}

Adena, M. et al. (2017) 'Quality certifications for nonprofits, charitable giving, and donor's trust: Experimental evidence', WZB Working Paper SP II 2017-302.

Adena, M. and Hager, A. (2020) 'Does online fundraising increase charitable giving? A nation-wide field experiment on Facebook video fundraising'. WZB Working Paper SP II 2020-302.

Adena, M., Hakimov, R. and Huck, S. (2019) 'Charitable giving by the poor. A large-scale field experiment in Kyrgyzstan’. WZB Discussion Paper No. SP II 2019-306r.

Adena, M. and Huck, S. (2017) 'Matching donations without crowding out? Some theoretical considerations, a field, and a lab experiment', Journal of Public Economics, 148(April), pp. 32-42. doi: 10.1016/j. jpubeco.2017.02.002.

Adena, M. and Huck, S. (2019a) 'Giving once, giving twice: A two-period field experiment on intertemporal crowding in charitable giving', Journal of Public Economics, 172, pp. 127-134. doi: 10.1016/j. jpubeco.2019.01.002.

Adena, M. and Huck, S. (2019b) 'Personalized fundraising: A field experiment on threshold matching of donations'. WZB Working Paper No SP II 2019-306.

Adena, M., Huck, S. and Rasul, I. (2014) 'Charitable giving and nonbinding contribution-level suggestions evidence from a field experiment', Review of Behavioral Economics, 1(3), pp. 275-293. doi: 10.1561/105.00000010.

Andreoni, J. (1990) 'Impure altruism and donations to public goods: A theory of warm-glow giving', The Economic Journal, 100(401), p. 464. doi: 10.2307/2234133.

Andreoni, J. and Payne, A. A. (2003) 'Do government grants to private charities crowd out giving or fundraising?' American Economic Review, 93(3), pp. 792-812. doi: 10.1257/000282803322157098. 
Becchetti, L., Pelligra, V. and Reggiani, T. (2017) 'Information, belief elicitation and threshold effects in the 5X1000 tax scheme: A framed field experiment', International Tax and Public Finance, 24(6), pp. 1026-1049. doi: 10.1007/s10797-017-9474-z.

Bott, K. M. et al. (2019) 'You've got mail: A randomized field experiment on tax evasion', Management Science, 66(7), pp. 2801-2819. doi: 10.1287/mnsc.2019.3390.

Casarico, A. and Tonin, M. (2018) Pay-what-you-want to support independent information - a field experiment on motivation, IZA Discussion Paper.

Castillo, M. and Petrie, R. (2021) 'Optimal incentives to give'. IZA Discussion Paper 13321. doi: 10.2139/ ssrn. 3616460

Davis, D. D. (2006) 'Rebate subsidies, matching subsidies and isolation effects', Judgment and Decision Making, 1, pp. 13-22.

Diederich, J. et al. (2020) 'Subsidizing unit donations: Matches, rebates, and discounts compared'. AWI Discussion Paper Series No. 697. doi: 10.11588/heidok.00029236.

Dwenger, N. et al. (2016) 'Extrinsic and intrinsic motivations for tax compliance: Evidence from a field experiment in Germany', American Economic Journal: Economic Policy, 8(3), pp. 203-232. doi: 10.1257/ pol.20150083.

Eckel, C. and Grossman, P. J. (2003) 'Rebate versus matching: Does how we subsidize charitable contributions matter?' Journal of Public Economics, 87(3-4), pp. 681-701. doi: 10.1016/S0047-2727(01)00094-9.

Eckel, C. and Grossman, P. J. (2006) 'Subsidizing charitable giving with rebates or matching: Further laboratory evidence', Southern Economic Journal, 72(4), p. 794. doi: 10.2307/20111853.

Eckel, C. and Grossman, P. J. (2008) 'Subsidizing charitable contributions: A natural field experiment comparing matching and rebate subsidies', Experimental Economics, 11(3), pp. 234-252. doi: 10.1007/ s10683-008-9198-0.

Eckel, C. and Grossman, P. J. (2017) 'Comparing rebate and matching subsidies controlling for donors' awareness: Evidence from the field', Journal of Behavioral and Experimental Economics, 66, pp. 88-95. doi: 10.1016/J.SOCEC.2016.04.016.

Epperson, R. and Reif, C. (2019) 'Matching subsidies and voluntary contributions: A review', Journal of Economic Surveys, pp. 1-24. doi: 10.1111/joes.12337.

Gallier, C. et al. (2019) 'Inter-charity competition under spatial differentiation: Sorting, crowding, and spillovers'. ZEW-Centre for European Economic Research Discussion Paper 19-039.

Gangl, K. et al. (2014) 'Effects of supervision on tax compliance: Evidence from a field experiment in Austria', Economics Letters, 123(3), pp. 378-382. doi: 10.1016/j.econlet.2014.03.027.

Gee, L. and Meer, J. (2020). '24. The Altruism budget: Measuring and encouraging charitable giving', in W. Powell and P. Bromley (eds.). The Nonprofit Sector: A Research Handbook, Third Edition (pp. 558-565). Redwood City: Stanford University Press. doi: 10.1515/9781503611085-033.

Gneezy, U., Keenan, E. A. and Gneezy, A. (2014) 'Avoiding overhead aversion in charity', Science, 346(6209), pp. 632-635. doi: 10.1126/science.1253932.

Heger, S. A. and Cornish, A. D. (2021) Vice and virtue behaviours: Substitution and non-substitution effects. New York: Mimeo.

Heger, S. A. and Slonim, R. (2020) Altruism begets altruism. New York: Mimeo.

Huck, S. and Rasul, I. (2011) 'Matched fundraising: Evidence from a natural field experiment', Journal of Public Economics, 95(5-6), pp. 351-362. doi: 10.1016/j.jpubeco.2010.10.005.

Huck, S., Rasul, I. and Shephard, A. (2015) 'Comparing charitable fundraising schemes: Evidence from a natural field experiment and a structural model', American Economic Journal: Economic Policy, 7(2), pp. 326-369. doi: 10.1257/pol.20120312.

Iyer, G. S. et al. (2010) 'Increasing tax compliance in Washington state: A field experiment', National Tax Journal, 63(1), pp. 7-32.

Karlan, D. and List, J. A. (2007) 'Does price matter in charitable giving? Evidence from a large-scale natural field experiment', American Economic Review, 97(5), pp. 1774-1793. doi: 10.1257/aer.97.5.1774.

Karlan, D., List, J. A. and Shafir, E. (2011) 'Small matches and charitable giving: Evidence from a natural field experiment', Journal of Public Economics. doi: 10.1016/j.jpubeco.2010.11.024.

Kesternich, M., Löschel, A. and Römer, D. (2016) 'The long-term impact of matching and rebate subsidies when public goods are impure: Field experimental evidence from the carbon offsetting market', Journal of Public Economics, 137, pp. 70-78. doi: 10.1016/j.jpubeco.2016.01.004.

Lacetera, N., Macis, M. and Slonim, R. (2012) 'Will there be blood? Incentives and substitution effects in pro-social behavior', American Economic Journal: Economic Policy, 4(1), pp. 186-223. doi: 10.1257/ pol.4.1.186. 
List, J. A. (2008) 'Introduction to field experiments in economics with applications to the economics of charity', Experimental Economics, 11(3), pp. 203-212. doi: 10.1007/s10683-008-9201-9.

List, J. A. and Lucking-Reiley, D. (2002) 'The effects of seed money and refunds on charitable giving: Experimental evidence from a university capital campaign', Journal of Political Economy, 110(1), pp. 215-233. doi: 10.1086/324392.

Meier, S. (2007) 'Do subsidies increase charitable giving in the long run? Matching donations in a field experiment', Journal of the European Economic Association, 5(6), pp. 1203-1222.

Ottoni-Wilhelm, M. and Hungerman, D. M. (2021) 'Impure impact giving: Theory and evidence', Journal of Political Economy, 129(5), pp. 1553-1614.

Rondeau, D. and List, J. A. (2008) 'Matching and challenge gifts to charity: Evidence from laboratory and natural field experiments', Experimental Economics. doi: 10.1007/s10683-007-9190-0.

Saez, E. (2004) 'The optimal treatment of tax expenditures', Journal of Public Economics, 88(12), pp. 26572684. doi: 10.1016/j.jpubeco.2003.09.004.

Schmitz, J. (2021) 'Is charitable giving a zero sum game? - The effect of competition between charities on giving behavior', Management Science. doi: 10.2139/ssrn.2862479.

Shang, J. and Croson, R. (2009) 'A field experiment in charitable contribution: The impact of social information on the voluntary provision of public goods', The Economic Journal, 119(October), pp. 14221439. doi: 10.1111/j.1468-0297.2009.02267.x.

Teirlinck, M. (2020) Tax incentives for charitable giving : Information frictions and hassle costs. New York: Mimeo.

Thaler, Richard H., and Sunstein, Cass R. (2008) Nudge: Improving decisions about health, wealth, and happiness. London: Penguin Books.

Vesterlund, L. (2003) 'The informational value of sequential fundraising', Journal of Public Economics, 87, pp. 627-657. doi: 10.1016/j.envexpbot.2012.01.010.

Vesterlund, L. (2016) 'Using experimental methods to understand why and how we give to charity', in John H. Kagel and A. E. Roth (eds.) The Handbook of Experimental Economics, Volume 2 (pp. 91-152). Princeton: Princeton University Press. 